\title{
Gender Equality Is the Path to Social Justice--Analysis from the Perspective of Gender
}

\author{
Dan Li \\ Yunnan labor union communist youth league women's federation cadre school, Yunnan, China. \\ 285295989@qq.com
}

\begin{abstract}
Gender mainstreaming, as an effective strategy to realize gender equality, has become a guideline for the cause of gender equality and women's development and the promotion of public policy in China. Integrating gender equality and women's development into the strategy of harmonious society; Give full play to the leading and regulatory role of the government; Improving women's participation in government; Attach importance to safeguarding women's personal rights and health rights; Building and advocating an advanced gender culture of equality, harmony and civilization; Only by making gender sensitive indicators can we finally realize the socialist harmonious society of gender equality. This paper first analyzes the concept of gender consciousness, provides an overview of the international and domestic social gender mainstream trend and role, and the second is gender consciousness to promote social justice and public policy, finally to use gender Angle of view to promote public policy, which involved in the social governance provides certain ideas and Suggestions to work.
\end{abstract}

Keywords: Gender consciousness; Public policy; Social justice.

\section{Introduction}

As an effective strategy to realize gender equality, gender mainstreaming has become a guideline for China's social gender equality and women's development and the promotion of public policies. Integrating gender equality and women's development into the strategy of harmonious society; Give full play to the leading and regulatory role of the government; Improving women's participation in government; Attach importance to safeguarding women's personal rights and health rights; Building and advocating an advanced gender culture of equality, harmony and civilization; Only by making gender sensitive indicators can we finally realize the socialist harmonious society of gender equality. This paper first analyzes the concept of gender consciousness, provides an overview of the international and domestic social gender mainstream trend and role, and the second is gender consciousness to promote social justice and public policy, finally to domestic structural reform under the background in gender perspective to push related public policy, which involved in the social governance provides certain ideas and Suggestions to work.

\section{Gender Awareness}

Gender in English is gender, as opposed to sex. "Sex" refers to the inherent biological nature of male and female, while "gender" is a cultural construct, which develops from the role of social practice and leads to differences in roles, behaviors, thoughts and emotional characteristics between males and females. The term "social gender" was first coined by us anthropologist Gayle Rubin and is a tool for social and cultural analysis.

\subsection{Gender Mainstreaming}

The mainstreaming of gender awareness, also known as mainstreaming gender awareness into social development and decision-making, was first reflected in the Nairobi strategy adopted by the third world conference on women in 1985 and in the programmer of action adopted by the fourth world conference on women in 1995. The word "gender mainstream consciousness" is the English gender mainstreaming in translation, is refers to the government, organization or agency in policy formulation, implementation and evaluation, as well as the daily work, considering the gender of the different influence on men and women, to gradually eliminate gender discrimination and achieve the 
goal of gender equality and gender justice. At this conference, the United Nations identified gender mainstreaming in all areas of social development as a global strategy for gender equality. Generally speaking, social gender equality means that all social members are free to develop their personal abilities and make various choices without being restricted by the concept of the division of social gender roles, as well as all kinds of discrimination and prejudice. Different behaviors, expectations and needs of men and women can be equally considered, evaluated and cared for. It is an important goal to gradually eliminate gender discrimination and realize gender equality and social gender justice. However, gender mainstreaming is not a goal in itself, but a means to achieve gender equality in society.

Traditional social policy often has the gender blind spots for all sorts of factors, in the part of the male society, women have always been difficult to enter the center of decision making, in terms of the level, gender consciousness into the decision-making mainstream "is actually a logical extension of the social gender theory, is also the reality of social gender theory and concrete.

\subsection{Mainstreaming of Gender Consciousness and Public Policy}

The issue of gender equality has always been a priority area of concern for the United Nations, as stated in the preamble to the charter of the United Nations: "reaffirms the belief in fundamental human rights, human dignity and values, and the equal rights of men, women and small states." "Mainstreaming gender issues is a process that analyzes the impact on women and men of any planned action at all levels in any field, including legislation, policies or project plans. It is a strategy that considers the concerns and experiences of women and men as an integral part of the design, implementation, follow-up, evaluation of policies and project plans in the political, economic and social fields, so that women and men benefit equally and that inequality does not continue. Its ultimate goal is to achieve gender equality. The elimination of gender discrimination has become a major concern of the international community and gender mainstreaming has become a global strategy for all countries in the world.

In 1946, the United Nations economic and social council established a 15-member commission on the status of women (expanded to 45 in 1991). The United Nations adopted the convention on the political rights of women in December 1952, reaffirming the principle of equality between men and women embodied in the charter of the United Nations, which stipulates that all men and women are equal and there is no discrimination. Subsequently, in 1967, the United Nations adopted the declaration on the elimination of discrimination against women and designated 1975 as the international year of women, with the goals of equality, development and peace. In the same year, the first world conference on women was held in Mexico's capital, Mexico City. The 1979 United Nations convention on the elimination of all forms of discrimination against women further states that discrimination against women violates the principle of equal rights, hinders women and men from participating in the political, social, economic and cultural life of their countries on equal terms, and impedes the prosperity and development of society and the family. States parties are to clarify their obligations, take all appropriate and special measures to change the traditional tasks of men and women in society and in the family, eliminate discrimination against women and achieve full equality between men and women. Based on the strong support of "gender equality is the basic national policy", in February 2004, the United Nations launched the "Beijing +10" plan, which comprehensively reviewed the implementation of the Beijing programmer of action by governments and drew up a new blueprint for gender equality since the fourth world conference on women (1995) and the special session of the "Beijing +5". In 2005, the 39th United Nations conference on the status of women held a high-level roundtable to assess and discuss "mechanisms for the advancement of women". The report of UN secretary-general Kofi Annan at that time also has a special chapter, review and evaluation this issue shows the important role it plays in fulfilling commitments to governments and implementing the Beijing programmer of action. The strategy of promoting gender mainstreaming and realizing gender equality has become an international consensus. At the fourth world conference on women in 2016, the United Nations not only proposed a global strategy to achieve gender equality, but also emphasized mechanisms, budgetary support, capacity building and information building. 
With the continuous improvement and development of modern government system, the application of gender consciousness in public policy making has been paid more and more attention. The public policies formulated by governments have an important impact on the distribution of public interests and the regulation of public behavior. In order to ensure the basic right to life and development of every member of society, it is considered necessary to eliminate a series of social problems caused by "gender inequality" in the form of public policy.

\section{Social Justice and Gender Discrimination}

Social justice is an important index to measure the overall progress and development of society. Gender justice is to enable men and women to participate, contribute and share the fruits of development on an equal footing. If one gender has more participation, contribution and opportunity to benefit, and the other gender is marginalized or impoverished, it is not social justice at all. The international Labor organization (ill) has defined gender discrimination as the practice of discrimination, exclusion or preferential treatment based on physical or social gender (or other social criteria, such as national, skin color, religious or political views) so as to deny equal opportunities and treatment to both sexes. Gender discrimination is not only manifested in all stages of women's life cycle, but also in employment, human resource development, social participation and other fields.

Take education for example. According to the United Nations, the education gap between men and women has disappeared in developed countries, with Japan, Sweden, Finland and other countries having higher female enrollment rates than men. Women in developing countries are less likely to receive education than men, and the gender gap is striking. In the 10 years from 2001 to 2010, education of preschool education in Yunnan province has changed greatly in its development scale and growth range. In 2009, the number of preschool children in kindergartens in the province was the same regardless of gender in the education stage the total number of children in kindergartens increased steadily from 604,000 in 2000 to 987,000 in 2010, an increase of 383,000, and an increase of $63.5 \%$ over 2000 . The gross enrollment rate of pre-school education increased from 54.5 percent in 2009 to 59.6 percent in 2010, an increase of more than 5 percent in a year. However, by gender, the number of girls in kindergartens in 2010 was still lower than that of boys, 529,000 boys and 458,000 girls.

In terms of income ratios, women in all countries earn significantly less than men. The World Economic Forum's Global Gender Gap report for 2015, released by BBS on November 18, 2015, shows that there is a small Gap between the social status and income treatment of men and women in the Nordic countries. The top four countries in the list are all Nordic countries, including Iceland, Norway, Finland and Sweden. The highest-ranked Asian country is the Philippines, which ranks seventh. China ranks 91, Japan 101 and South Korea 115. Middle Eastern countries were at the bottom of the list, with Egypt at the bottom. CNN reports men in the United States the women's income gap index is $64 \%$, which means that women earn only $64 \%$ of their male counterparts. This is worse than $66 \%$ last year. The report found that in no country men and women are paid the same. Women in Brazil and Angola earn less than half as much as their male counterparts. The report, which surveyed the number of female chief executives worldwide, found that women in 100 countries were more likely than men to receive higher levels of education, but only four countries had female leaders and chief executives. The report also shows that the income gap between men and women has been slow to change, with women now making on average the same amount of money as men for 10 years, according to annual income surveys. The world economy reckons it will take another 118 years, or 2133, before the income gap between men and women comes closest. In addition, in the human development report (2016), the United Nations proposed an indicator: gender development index. The closer the score is to 1, the more equal the men and women are. Sweden and Finland already have a gender development index of more than 0.9 , while some developing countries are still far from gender equality. China's gender development index is only 0.578 . Despite the high level of equality between men and women in the Nordic countries, no country has achieved full equality between men and women in education, income and power. French scholar Lenoir's 1974 concept of "social 
exclusion", mainly used to describe phenomena in the economic field, has been widely used in various fields of economy and society to study the relationship between edge and center, acceptance and acceptance, rejection and integration. Due to the deprivation of certain rights, opportunities and resources, the participation of a certain social group is insufficient and interrupted. This is the main manifestation of social exclusion. After studying the relationship between social exclusion and gender, feminism points out that gender is a key factor in the distribution of jobs, wealth and other social resources. For example, women are subject to employment discrimination, are placed in unskilled positions, are in temporary working conditions such as part-time jobs, and may be targeted for sexual harassment regardless of their position or educational status. They also believe that giving the same treatment to people who are sexually disadvantaged often reinforces their disadvantages. If the effects of such equal treatment are radically different and there is no good reason why it is necessary, then it can be considered an indirect form of discrimination.

\section{The Representation of Gender Consciousness in China's Public Policy}

Public policy, as the external output subsystem of the political system, is broadly defined as the regulation and distribution of the public interest and public behavior formulated by the government and legislative organs, including laws, regulations, rules and regulations. In a narrow sense, it refers to the regulation and distribution measures of government and other policy-making departments on the public interest and public behavior. The study on the combination of social gender consciousness and public policy can permeate social consciousness in the formulation of public policy and enhance the gender sensitivity of decision-makers.

For our country, gender equality was written into the constitution in 1954. From 1995, comrade kiang Zemin at the opening ceremony of the fourth world conference specifically, to the rights and interests protection ordinance, revised in 2005 to 2012 in the report, the party's 18 equality of basic national policy from the government's commitment to "legislative confirmation" to "the ruling party will" all-round "certification". Equality between men and women refers to the equal rights and obligations of both sexes in marriage and family relations. Article 48, paragraph 1, of the constitution of the People's Republic of China states clearly that men and women in the People's Republic of China enjoy equal rights in political, economic, cultural, social and family life. In November 2012, the 18th CPC national congress included gender equality as the basic state policy for the first time. Nineteen reports were also written again.

In 1980, China signed the United Nations convention on the elimination of all forms of discrimination against women (hereinafter referred to as the "disambiguation convention"). This convention is the most important platform for women's organizations of various countries to promote gender equality in recent decades. The Chinese government, like other states parties, should submit regular reports on the implementation of the convention to the United Nations and read them out at the general assembly. In addition to providing theoretical support for gender equality at the level of macro public opinion, it also plays an international role of accountability to a government. My government is often urged by the committee on the convention on disambiguation to implement the specific definition of "discrimination" in its national laws as soon as possible in order to promote substantive equality between men and women. Because although the constitution of our country and "women's rights and interests protection law" provisions of the "women and men in politics, economy, social life and so on various aspects have equal rights", but this clause is too abstract, form is greater than the essence, can't really change the income gap between men and women, gender segregation, violence against women and substantive inequality.

After years of promotion and appeals, on the eve of the 2013 college entrance examination, China's ministry of education issued the 2013 regulations on enrollment of ordinary institutions of higher learning, which stipulates that "except some special institutions (majors) such as military, national defense and national security, colleges and universities shall not stipulate the enrollment ratio of male and female students." The rules make it clear for the first time that foreign language and broadcasting majors cannot set a sex ratio. Although women's media monitoring network 2014 study showed that 
there are still 27 provinces and cities in 66 "211" universities exist different degrees of gender discrimination, $59 \%$ of the school, but in recent years issued by ministry of education of the ministry of education about for 2016 session of the national ordinary institutions of higher learning graduates employment entrepreneurship work notice, first make clear a regulation: "all campus recruitment activities are strictly forbidden to release contains qualified institutions, such as gender, ethnic discrimination information." The above policy changes show that, even in the current situation of imperfect laws and regulations, the existing policies can be changed to a certain extent once pressure is exerted on relevant departments to implement gender equality laws and regulations.

\section{A Brief Analysis of Social Gender Consciousness Into the Mainstream of Decision-Making to Achieve Social Justice}

Gender awareness is embodied in social policies and legislation. In the process of decision-making (including setting decision-making goals, establishing decision-making plans, collecting data and analyzing evidence, evaluating feasibility and possible consequences), the implementation of gender awareness and its inclusion in decision-making will have a profound impact on the development of both sexes? Some of the usual research and push is actually doing the following:

\subsection{Strengthen Gender Awareness of Male-Dominated Leadership}

Policy-makers have a sense of gender and can be keenly aware of the existence of gender structure in society. It has a gender perspective and gender sensitivity in decision-making and pays close attention to the possible impact of new decision-making on vulnerable women and takes corresponding measures. It not only focuses on the current interests of women, but also pays attention to and promotes the long-term development of women. In Canada, law making officers of the legislative council are trained in gender awareness, and an examination is set up to identify whether there are gender-awareness inspectors in the legislation. In China, we rely on women's federations and women's research scholars to give advice and appropriate training to policy-makers on gender awareness. Media, especially under the developing and strengthening institutional reform period of the new media network is one of the important position, promote social gender consciousness by using "+" Internet platform and channel transmission applied social gender perspective, not only work in extending tentacles, is scientific and objective gender Angle of view consciousness gradually infiltrated the executive decisions, which can promote its influence on public policy.

The most practical case at present is the notice of Yunnan provincial people's government on issuing the three-year action plan (2018-2020) for the "toilet revolution" in Yunnan province issued by Yunnan provincial government on July 17, 2018. The total number of public toilets and tourist toilets in urban and rural areas in Yunnan province is expected to reach 34,000 by 2020. Renovate and build 2.5 million sanitary toilets in rural areas. Scientific planning of urban and rural public toilets, reasonable layout, and pedestrians can walk 3-5 minutes to enter public toilets; adjust the ratio of men's and women's toilets. The ratio of women's toilets to men's toilets in general urban areas and railway passenger stations should reach more than 3:2, and the ratio of women's toilets to men's toilets in crowded places such as commercial areas, sports venues, airports and other transportation hubs should reach more than 2:1. This means: after three or five minutes in Yunnan can be easily found public toilets, and women's toilets long queue men's toilets empty scene can be changed!

\subsection{Improve Women's Awareness and Level of Participation in Politics and Discussion}

First, increase the proportion of women in decision-making. Consider quantifying women's participation in politics in the use of open selection and promotion. Secondly, to improve the quality of women in participating in politics is to enter the core of decision-making. At present, there is a situation in China where women are marginalized. Most of them are placed at the outer edge of noncore positions and decision-making levels such as group organizations, and generally do not occupy important positions. In decision-making demonstration and discussion, the voice reflecting women's demands is weak and far away, and it is hard to truly represent women's interests. Therefore, changing 
the marginalized position of women at the decision-making level so that they can fully participate in the decision-making discussion and formulation at the most core level has far-reaching implications for the establishment of a public policy system with a gender perspective.

\subsection{Elimination of Gender Discrimination in Employment}

To eliminate gender discrimination in the field of employment, we must first actively promote gender mainstreaming in the field of labor employment and establish and improve policies on gender equality in the labor market. For example, we will promote the ratification of the convention against employment and occupational discrimination, the introduction of the gender equal employment law, and further improve the social security system and the social support system for women's employment. Promoting the establishment of the equal employment system, which in turn affects the field of women's education, is essential to eliminate gender discrimination in the field of education and employment. Although it is difficult to change people's preferences by relying on the law, establishing a framework without discriminatory preferences through the law can play a powerful restrictive role, and also play a policy role in guiding the establishment of gender equality awareness.

\subsection{Elimination of Gender Discrimination in the Talent Mechanism}

Gender discrimination is widespread in education, education, selection and employment. First, it is reflected in education opportunities. In the field of non-basic education, the gender distribution of majors (for example, in the relevant education training, women's majors are concentrated in the lower income category); in the area of employment and vocational training, "gender segregation continues to affect the career development of women; insufficient investment in women's training limits women's opportunities for self-development. Information society, change in a short time, professional skills to keep pace with The Times is a subject that needs constant attention from all walks of life. In sex education development in Yunnan province, vocational skills training of age and life skills training, guide the Yunnan women on the level of all age groups and the society as much as possible to participate in all aspects of social life, expanded the presence of women's equal participation in social labor, improve some of the women's economic and social status, full access to the happiness of life.

In order to eliminate gender discrimination against women still exists obvious, realize the gender equality of education and training, suggested that the government efforts from the following aspects: first, the gender equality consciousness into the basic education, on the basis of education, regulations and policies on gender analysis, correcting the current education, regulations and policies of the gender blind spots, we will improve the mechanism of compulsory education management. Second, we should vigorously reverse the unbalanced trend of basic education resources, narrow the differences between different regions, and ensure the education resources in rural areas. Special policies are in place to protect girls' right to education. Third, the government could take stronger measures to reduce the gender gap in access to education opportunities and the gender gap in employment opportunities and returns on education in the Labor market, especially by increasing the rate of return on education for the female base. Fourth, develop non-discriminatory education and integrate gender awareness into national education -- starting with the training of textbook writers, education managers and teachers, so as to enhance their gender equality awareness and concept. Fifth, pay attention to the role of female teachers, especially the survival and development of female teachers in rural poor areas and ethnic minority areas. Increase the number of women in executive leadership at all levels of schools and education and enhance their gender awareness in leadership areas. In addition, gender issues should be fully taken into account in the provision of resources for job creation and training for employability enhancement, as well as in the in-service training of institutions, so that men and women have equal opportunities for training and lifelong education.

\subsection{General}

The social justice that all beings yearn for is the most important part of the ideal social form. Social justice is mainly reflected in the justice among the members of the society. No matter how the social 
component is divided, the most basic distinction is still attributed to the biological nature. If either sex is not treated fairly, the society will not be a truly just society. In addition, though gender equality is the ideal goal of feminist, but the gender equality is not absolute equality between men and women on the social achievements of sharing, more refers to men and women in education resources, equal employment opportunities and development, to participate in social activities, social achievements sharing and the principle of procedural justice, to realize the social justice, in the current era of history, the best path and the way or through and all aspects of efforts to promote and influence, make balance and science of public policy, with the most appropriate social governance, make the vision become reality! Make the relationship truly symbiotic and win-win!

\section{References}

[1]. Ma yen. Gender awareness and women's development in China's public policy [J]. Theoretical guide, 2004(5):120-122.

[2]. Lieu fifer. Analysis on gender consciousness in public policy [D]. Shanghai normal university, 2006.

[3]. Chen wee, ran qi. Social gender in public policy [J]. Journal of Gansu institute of political science and law, 2005.

[4]. So dourine. On gender consciousness in China's public policy [J]. Qinghai social science, 2010(1):66-68.

[5]. Li haying. A summary of the discussion on social gender and public policy issues [J]. Theoretical front, 2001, (23). 